\title{
Estudos socioambientais em áreas assistidas pela transposição do rio São Francisco no semiárido - enfoque na sustentabilidade e nas (in) viabilidades do percurso
}

\section{Studies in environmental areas aided by incorporation of São Francisco river in semiarid - focus on sustainability and the (in) viabilidades route}

\author{
Antonia Arisdélia Fonseca Matias Aguiar Feitosa' $(*)$ \\ Tatiana Marinho Gadelha ${ }^{2}$ \\ Juciany de Sousa Guerra ${ }^{3}$
}

\section{Resumo}

Na região Semiárida do Nordeste brasileiro, a escassez hídrica associada à incerteza climática mantém limitadas as atividades básicas, o abastecimento das populações e o desenvolvimento das atividades agrícolas e industriais. A implantação de sistemas de armazenamento e transposição de águas, como o Projeto de Transposição do Rio São Francisco, tem como meta assegurar o suprimento e distribuição de água para as necessidades humanas, possibilitando o desenvolvimento socioeconômico da região semiárida nordestina. Por outro lado, também contribui gerando problemas socioambientais, cujas soluções demandam processos educativos voltados à gestão e à conservação ambiental. Essa pesquisa tem como objetivo analisar os impactos socioambientais provocados nas áreas assistidas pela transposição do Rio São Francisco. A pesquisa foi realizada nas Vilas Produtivas Rurais do município de São José de Piranhas no interior da Paraíba - PB, através de "análise de conteúdo" e "estudo de caso" baseados em documentos técnicos, entrevistas, observações e registros de imagem com ênfase nas questões socioambientais. Os estudos sobre esses aspectos socioambientais com as famílias reassentadas nas Vilas mostram que elas possuem pouca informação, algumas insatisfações e grande expectativa em relação a sua nova realidade, e isso gera conhecimentos necessários para um processo de gestão participativa e ambiental numa perspectiva de sustentabilidade.

Palavras-chave: Transposição de Águas; Vilas Produtivas Rurais; Comunidades Reassentadas.

1 Dra.; Educação; Universidade Federal da Paraíba, UFPB, Brasil; Professora Adjunto do Departamento de Sistemática e Ecologia do CCEN da Universidade Federal da Paraíba; Endereço: Universidade Federal da Paraíba, Centro de Ciências Exatas e da Natureza - Campus I. AC Cidade Universitária João Pessoa Castelo Branco. CEP: 58051970 - João Pessoa, PB - Brasil; E-mail: arisdelfeitosa@gmail.com $\left(^{*}\right)$ Autor para correspondências

2 Graduação em Ciências Biológicas; Universidade Federal de Campina Grande, UFCG, Brasil; Endereço: Universidade Federal de Campina Grande, Centro de Formação de Professores. Rua Sérgio Moreira S/N, Casas Populares. CEP: 58900000 - Cajazeiras, PB - Brasil; E-mail: tatianamarinho08@hotmail.com

3 Graduação em Ciências Biológicas; Universidade Federal de Campina Grande, UFCG, Brasil; Endereço: Universidade Federal de Campina Grande, Centro de Formação de Professores. Rua Sérgio Moreira S/N, Casas Populares. CEP: 58900000 - Cajazeiras, PB - Brasil; E-mail: juciany_guerra@hotmail.com

\begin{tabular}{llllll}
\hline Ambiência & Guarapuava (PR) v.I5 n.I & p. $40-56$ & Jan/Abr 2019 & ISSN 1808 - 025I
\end{tabular}




\section{Abstract}

In the semi-arid region in the northeast of Brazil, the water shortages associated with climate uncertainty maintain basic activities limited as also the supply to the population and the development of agricultural and industrial activities. The installation of systems to divert and storage water, such as the São Francisco River diversion project, aims to ensure the supply and distribution of water for human needs, enabling the socioeconomic development of the region, on the other hand, induces social and environmental problems whose solutions require educational processes focused upon the environmental management and conservation. This research aims to analyze the social and environmental impacts in the areas assisted by the diversion of the São Francisco River. The survey was conducted in the Rural Productive Villages in county São José de Piranhas, state of Paraíba (PB), through "content analysis" and "case study" based on technical documents, interviews, observation and image records with emphasis upon environmental issues. Studies about these environmental aspects with families resettled in the villages, show that they are likely to be misinformed, also they showed some dissatisfactions, but also great expectations for their new reality and, in this way, all of this generates the need for knowledge for a management process with participation and environmental care, under a sustainability perspective.

Keywords: Water diversion; Rural Productive Villages; Resettled communities

\section{Introdução}

A área do semiárido ocupa 70\% do Nordeste brasileiro e corresponde a 11\% do território nacional. Nesses espaços, o índice de chuvas é de $600 \mathrm{~mm}$ anuais em média. A escassez de água, associada à incerteza climática mantêm limitadas as atividades básicas, o abastecimento das populações e o desenvolvimento das atividades agrícolas e industriais.

No Nordeste, as grandes porções territoriais caracterizadas por clima semiárido possuem mananciais que não oferecem garantia de água para os vários tipos de usos dos recursos hídricos. Sem água, essa região estará fadada ao subdesenvolvimento, restando - lhe poucas alternativas de desenvolvimento econômico e social.

A água, recurso indispensável à vida dos seres vivos, vem sofrendo grandes impactos, os quais comprometem a sua qualidade e sua disponibilidade. Podemos destacar alguns causadores desses impactos, tais como: a escassez generalizada da água, o aumento da poluição e o mau uso desses recursos, a falta de uma gestão sustentável. Tais indicadores nos levam a perceber a importância da água para o nordeste e a necessidade de um sistema racional de uso desse recurso.

A implantação de sistemas de armazenamento e transposição de águas tem como meta assegurar o suprimento e distribuição de água para as necessidades humanas dos municípios cuja escassez hídrica limita as atividades produtivas, econômicas e de subsistência em comunidades da região semiárida.

O Projeto de Integração do Rio São Francisco com Bacias, Hidrográficas do Nordeste Setentrional visa atender às necessidades da população e promover o desenvolvimento socioeconômico dos estados mais vulneráveis às secas - Ceará, Paraíba, Pernambuco e Rio 
Grande do Norte. Entretanto, suas obras envolvem profundas modificações nas paisagens naturais do ambiente semiárido e na constituição de comunidades presentes nas áreas suscetíveis de intervenções.

Tais modificações demandaram a elaboração e implementação de um conjunto de programas ambientais nos quais são apresentadas medidas mitigadoras para enfrentar os impactos socioambientais advindos da implantação do Projeto de Integração do Rio São Francisco com Bacias Hidrográficas do Nordeste Setentrional (PISF). Dentre os programas implementados, destacamos o Programa de Reassentamento das Populações (PBA-08), principal foco deste estudo.

O objetivo desta pesquisa foi analisar os impactos socioambientais em comunidades do semiárido advindos da implantação do Projeto de Transposição do Rio São Francisco, bem como identificar as (in)viabilidades nas propostas de desenvolvimento sustentável na região. De modo especifico, buscamos atender às seguintes indagações: Quais implicações socioambientais advêm da implementação do Projeto de Transposição? Qual o nível de organização previsto para as comunidades reassentadas? Como as populações reassentadas em vilas produtivas se sentem diante dessa mudança de vida?

O estudo traz contribuições para um processo de gestão participativa e a conservação das áreas semiárida no interior da Paraíba na perspectiva da sustentabilidade.

\section{A transposição das águas do Rio São Francisco e as possibilidades produtivas}

A limitação na oferta de água é uma questão crucial no que se relaciona ao desenvolvimento da região. Esse contexto vem sendo analisado por estudiosos e técnicos de forma que já estão sendo implantadas estratégias para aumentar a disponibilidade de água em algumas regiões que sofrem com a irregularidade das chuvas.

O Projeto de Integração do Rio São Francisco com Bacias Hidrográficas do Nordeste Setentrional é um empreendimento do Governo Federal sob a responsabilidade do Ministério da Integração Nacional. Trata-se de um empreendimento de infraestrutura hídrica onde dois sistemas independentes denominados de Eixo Norte e Eixo Leste captarão água do Rio São Francisco entre as barragens de Sobradinho e Itaparica.

O projeto está sendo implantado na área do polígono das secas (Figura 01), a área que mais sofre os efeitos de secas prolongadas, abrangendo parcialmente os estados de Pernambuco, Ceará, Paraíba e Rio Grande do Norte, objetivando beneficiar uma população de cerca de 12 milhões de pessoas. 


\section{Figura 01 - Localização do Projeto - regiões beneficiadas.}

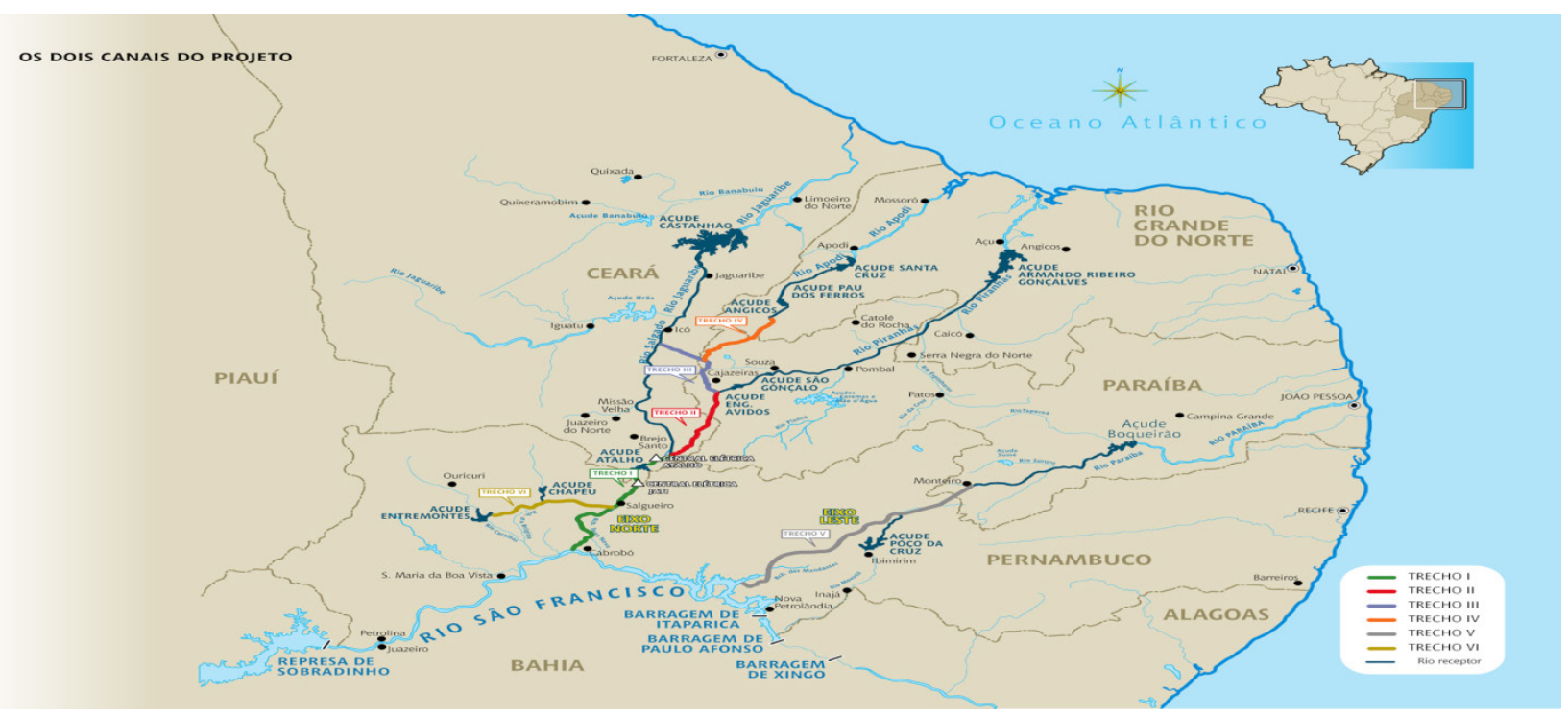

Fonte: (BRASIL, 2004).

A captação em Cabrobó dá início ao Eixo Norte. Esse Eixo tem uma extensão de aproximadamente $403 \mathrm{~km}$ e transportará um volume médio com cerca de 45,2 $\mathrm{m}^{3}$ de água por segundo, conduzindo para os rios Brígida (PE), Salgado (CE) Rio do Peixe e Piranhas-Açu (PB-RN) e Apodi (RN), além de garantir o fornecimento para os açudes importantes da região: Chapéu (PE), Entremontes (PE), Castanhão (CE), Engenheiros Ávidos (PB), Pau dos Ferros (RN), Santa Cruz (RN) e Armando Ribeiro Gonçalves (RN) (RIMA).

No ponto de captação em Itaparica, inicia-se o Eixo Leste, com cerca de $220 \mathrm{~km}$ indo até o Rio Paraíba, na Paraíba, transportando, em média, 18,3 m³ de água por segundo. Esse Eixo levará água para o açude Poço da Cruz (PE) e para o Rio Paraíba, que é responsável pela manutenção dos níveis do açude Epitácio Pessoa (PE), também chamado de Boqueirão (RIMA). Portanto, em longos períodos de estiagem, às águas do São Francisco garantirão o abastecimento humano à região. Nessa perspectiva, abre-se a possibilidade produtiva para as áreas a serem abastecidas.

A garantia hídrica viabilizará, por exemplo, a implementação de processos agroecológicos que emergem como forte aliado para se alcançar o desenvolvimento da região. A atividade agroecológica representa a base científica e uma adequada opção produtiva que se preocupacom a conservação ambiental, além de incorporar outros elementos mais amplos, como a promoção socioeconômica e cultural de agricultores que vivem em situação precária. Através da agricultura sustentável os produtores rurais são conduzidos a desenvolverem uma visão política crítica acerca dos modelos produtivos dominantes e serão capacitados a entenderem seu papel na sociedade (BRASILEIRO, 2006). É importante compreender que o alcance de tais mudanças está condicionado à forma de gestão a ser implementada nas áreas destinadas aos reassentamentos, bem como ao nível de organização social das comunidades beneficiadas. 


\section{Aspectos Gerais do Programa de Reassentamento das Populações}

O Programa de Reassentamento das Populações (PBA-08) é um dos 38 programas ambientais que constituem o Projeto Básico Ambiental (PBA), um conjunto de programas nos quais são apresentadas medidas mitigadoras para enfrentar os impactos ambientais e sociais, advindos da implantação do Projeto de Integração do Rio São Francisco com Bacias Hidrográficas do Nordeste Setentrional (PISF). Ele está articulado a outros programas socioeconômicos, que são, especificamente: Programa de Comunicação Social (PBA-03); Programa de Educação Ambiental (PBA-04); Programa de Indenização de Terras e Benfeitorias (PBA-07); Programa de Fornecimento de Água e Apoio Técnico para Pequenas Atividades de Irrigação ao Longo dos Canais para as Comunidades Agrícolas (PBA-16) e Programa de Prevenção à Desertificação (PBA-24).

O objetivo geral do Programa de Reassentamento das Populações (PBA-08) é propiciar, às famílias afetadas e participantes do processo de reassentamento, condições que permitam sua reprodução social e econômica em situação, no mínimo, similar à atual, sendo necessário, para isso, cumprir as seguintes metas previstas no documento: inclusão da totalidade das famílias elegíveis no processo de reassentamento; reassentamento de todas as famílias afetadas pelas obras dos canais, reservatórios e barragens antes do seu início; realização de capacitações periódicas com os temas de qualidade de vida; apoio à criação e o fortalecimento de associações de moradores em todas as Vilas Produtivas Rurais; transferência da gestão dos equipamentos sociais; promoção de assistência técnica.

As metas supramencionadas serão alcançadas mediante orientação de procedimentos que envolvem a seguintes etapas: Etapa 1 - Atividades Preliminares; Etapa 2 - Elaboração do Plano de Reassentamento; tapa 3 - Aprovação dos Planos de Reassentamento, opção pelas modalidades e pelos locais para o reassentamento; Etapa 4 - Atividades Preliminares para a Transferência das Famílias para Reassentamento Rurais Coletivos, envolvendo; Etapa 5 - Projeto Executivo das Vilas Produtivas e Execução das Obras; Etapa 6 - Transferências das Famílias; Etapa 7 - Apoio à Reinserção Socioeconômica das Famílias; Etapa 8 - Processo de Reassentamento em Áreas Remanescentes e de Famílias em Situação de Risco Social; Etapa 9 - Monitoramento e Avaliação do Programa.

Nos documentos oficiais que regem esse programa, pode-se constatar que não existem requisitos legais especificamente associados ao Programa de Reassentamento das Populações, já que as questões relacionadas à desapropriação e à indenização são tratadas no âmbito do Programa de Indenização de Terras e Benfeitorias. As condições que autorizam a desapropriação são previstos na Carta Magna: necessidade pública, utilidade pública ou interesse social, pagamento de indenização prévia, justa e em dinheiro, aplicável, no caso da desapropriação comum, e ainda, em títulos especiais da dívida pública correspondente a um valor justo, definido em lei, quando se tratar de desapropriação de latifúndio para fins de reforma agrária.

O publico alvo identificado para fazer parte desse programa de acordo com o PBA 08, são as famílias proprietárias e não proprietárias residentes nas áreas afetadas pelas obras, nos Trechos I e II do Eixo Norte, que abrange os municípios de Cabrobó, Terra Nova, Verdejante e Salgueiro, em Pernambuco; Pena forte, Jati, Brejo Santo, Mauriti e Barro no Ceará; Monte Horebe, São José de Piranhas e Cajazeiras, no estado da Paraíba, com um total de 1.132 áreas rurais afetadas, sendo 720 desapropriadas e o Trecho V do Eixo Leste, que abrange os municípios de Floresta, 
Custódia, Betânia e Sertânia, em Pernambuco e Monteiro, no Estado da Paraíba, com o total de 757 áreas rurais afetadas, sendo 125 desapropriadas.

Está registrado no documento que a maior proporção das famílias afetadas concentra-se no Eixo Norte, correspondendo a 85,2\% do total do Projeto, e nos estados de Pernambuco e Paraíba que são afetados pelos dois eixos desse empreendimento, com 37\% e 35,6\% de famílias a serem reassentadas respectivamente, já o Estado do Ceará, que é afetado apenas pelas obras do Eixo Norte, e residem cerca de 30\% dessas famílias, quando se analisa por município encentram-se em São José de Piranhas/PB (30,8\%) e Salgueiro/PE (18,2\%), no Eixo Norte e, em Sertânia/PE (9,8\%), no Eixo Leste, os maiores contingentes de famílias a serem relocadas pelo empreendimento.

Dentre as instituições envolvidas no programa, especialmente nas etapas de implantação dos reassentamentos e de reinserção socioeconômica dos reassentados nos novos locais de moradia, estão as Prefeituras Municipais para o planejamento na implantação da infraestrutura dos serviços sociais básicos nos locais de reassentamento; órgãos oficiais da região que oferecem assistência técnica e treinamentos aos produtores rurais como a EMBRAPA Semiárido, a Empresa Pernambucana de Pesquisa Agropecuária (IPA), a Empresa Estadual de Pesquisa da Paraíba (EMEPA) e a EMATER/Ceará; o SINE (Sistema Nacional de Emprego) oferecendo cursos de capacitação e requalificação profissional; programas de apoio ao desenvolvimento rural e de geração de renda como o PRONAF, Programa de Economia Solidária, o PROGER e ONG's (Organizações Não Governamentais) com atuação regional que desenvolvem ações e atividades junto a pequenos produtores rurais.

O programa de reassentamento informa, ainda, que existem alguns requisitos para que ocorra a desapropriação e consequentemente o reassentamento das populações, e não são todas as áreas afetadas pelo PISF que os correspondem. Além da residência na área a ser desapropriada, adotou-se, ainda, como critério de elegibilidade, o valor da indenização devida pelas terras e/ ou pelas benfeitorias a ser paga para as famílias proprietárias e das benfeitorias para as famílias não proprietárias. Esse valor foi definido a partir do levantamento do custo médio com o reassentamento, por família, em áreas rurais produtivas na região, considerando-se uma casa de alvenaria com $99 \mathrm{~m} 2$ (noventa e nove metros quadrados), infraestrutura associada e área produtiva, que foi estimada em $\mathrm{R} \$ 30.000,00$ (trinta mil reais).

A área na qual serão fixadas as residências foi definida em função do número médio de pessoas por família, que é de, no máximo, 5 pessoas entre as famílias residentes nas áreas a serem desapropriadas. É de se destacar que é usual, no caso de avaliações maiores (acima do valor das áreas produtiva e residencial oferecidas no reassentamento), as famílias optarem pela indenização, ocorrendo o inverso (avaliações menores) em relação às famílias que optam pelo reassentamento.

Segundo consta no Programa de Indenização de Terras e Benfeitorias (PBA-07), são mais de 25 mil hectares de áreas de imóveis rurais atingidas pela implantação dos canais e reservatórios do PISF que, conforme o Cadastro Fundiário e a Pesquisa Socioeconômica, realizados na atual fase de Projeto Básico Ambiental, e expostos no PBA-08, indicam que serão afetadas pelo projeto, parcial ou totalmente, 1.889 propriedades rurais, onde residem, nas áreas a serem desapropriadas, 273 famílias proprietárias e 572 famílias não proprietárias, totalizando 845 famílias. Esta estimativa foi realizada, considerando as faixas de 200 metros ao longo dos canais e 100 metros acima da cota máxima dos reservatórios, definidas como aquelas a serem necessariamente desapropriadas para a execução das obras. 
O processo de reinserção das famílias que foram desapropriadas de suas terras e encontra-se vulneráveis devido aos seus laços comunitários rompidos, demandará a realização de reuniões onde serão discutidas todas as duvidas sobre o "andamento das obras, o processo de reassentamento, a implantação das Vilas e ações indenizatórias", para que dessa forma possam adotar uma estratégia de reassentamento que seja, ao mesmo tempo, adequada às suas características socioeconômicas e culturais e garantia de condições e perspectivas melhores do que as que têm atualmente.

Conforme todo o estudo executado com essas famílias afetadas pelo projeto, foram elaborados quatro opções de reassentamento que consistem, nas modalidades: reassentamento em áreas remanescentes (transferência voluntária das famílias proprietárias de terras para áreas não afetadas da propriedade 'remanescentes'); auto reassentamento (famílias residentes na área a ser desapropriada, cujo valor da indenização de terras e/ou benfeitoras for superior a $\mathrm{R} \$ 30.000,00$ (trinta mil reais)); reassentamento coletivo rural (visa possibilitar a reprodução das relações sociais nos novos locais de moradia e produção, mantendo os vínculos de parentesco e de vizinhança existentes na área, para isso foram selecionadas preliminarmente, a partir do zoneamento da área de 2,5km em cada uma das margens dos canais, elaborado no Projeto Básico Ambiental, áreas com potencial para agricultura com base no potencial para irrigação do solo) e reassentamento em áreas urbanas (famílias em situação de risco social poderão ser identificadas alternativas individuais de relocação urbana em centros vizinhos).

Nesta perspectiva, o PBA-08 sugere que para minimizar os impactos socioeconômicos e culturais sobre população deslocada, e para que ocorra de forma adequada o Ministério da Integração Nacional (MI) entende ser necessário promover o reassentamento, conforme as premissas expostas no programa de reassentamento, considerando a participação das comunidades afetadas no processo de detalhamento, implantação e monitoramento do Programa.

\section{Gestão de Recursos Hídricos}

O termo Gestão vem do latim Gestione, que quer dizer, "ato de gerir, gerência, administração. A Gestão dos Recursos Hídricos é uma atividade voltada à formulação de documentos orientadores; à estruturação de sistemas gerenciais; e a tomada de decisões que têm o objetivo final de promover o uso, o controle e a proteção dos recursos hídricos”(LACERDA, 2003, p.19).

Essa gestão tem como finalidade conciliar recursos escassos com necessidades abundantes, ou seja, visa compatibilizar a oferta com a demanda, garantindo o uso múltiplo das águas para as atuais e futuras gerações de forma sustentável.

A gestão dos recursos hídricos ganhou força com a Lei das Águas (Lei Federal No 9433) e com instituição da Política Nacional dos Recursos Hídricos e dos seus instrumentos de gestão. Esta Lei busca assegurar disponibilidade de água de qualidade, utilizando racionalmente e integralmente esses recursos, tendo em vista um desenvolvimento sustentável e a prevenção da escassez de água.

De acordo com o relatório O Nosso Futuro Comum publicado em 1991(p.46) e elaborado pela Comissão Mundial em Meio Ambiente e Desenvolvimento, o desenvolvimento sustentável é aquele que atende às necessidades do presente sem comprometer a possibilidade de as gerações futuras atenderem as suas próprias necessidades.

Ainda de acordo com o relatório, para que haja um desenvolvimento sustentável, é preciso que todos tenham atendidos suas necessidades básicas e lhes sejam proporcionadas oportunidades 
de concretizar suas aspirações a uma vida melhor. Deste modo para alcançar o desenvolvimento sustentável dos recursos hídricos é necessário seu gerenciamento adequado.

Uma das inovações no processo de gestão dos recursos hídricos no Brasil relaciona-se com a forma participativa e descentralizada de lidar com este recurso essencial e indispensável para a vida. A forma participativa de gerenciar os recursos hídricos permite a sua efetivação.

Para Kummer (2007), o verbo "participar" significa tomar parte de um processo onde os indivíduos são os sujeitos. É um princípio e uma conquista básica da democracia, e possibilita que as pessoas tenham uma intervenção ativa e importante em todas as decisões que influenciem suas vidas. A participação é um processo democrático e sistêmico que acontece em grupos, projetos ou programas, e vai dar certo a partir do momento em que cada envolvido se sentir responsável pelo trabalho de seu grupo, projeto ou programa e, assim, pelo processo autodeterminante de desenvolvimento, ou seja, a partir do momento que as pessoas assumirem o papel de protagonistas deste processo para uma melhoria da qualidade de vida. A busca por fazer parte das decisões e reivindicações, bem como a luta por igualdade de oportunidades, são os caminhos para a almejada mudança.

De acordo com Lacerda (2003), para ser efetiva a gestão dos recursos hídricos deve ser concebido a partir da realidade da população e com ela serem discutidos e analisados todos os programas propostos, desde a sua fase inicial até o momento de implementação. Agindo desta forma amplia-se a possibilidade de que as mudanças sejam construídas/conquistadas coletivamente, de modo que a unidade de planejamento consiga alcançar o sucesso de uma gestão promotora da sustentabilidade dos recursos nesse espaço.

Ainda de acordo com a autora:

Um modelo de integração participativa se caracteriza como uma estrutura na forma de uma matriz de gerenciamento, responsável pela execução de funções gerencias especificas e pela adoção de três instrumentos: $1^{\circ}$ ) o planejamento estratégico por bacia hidrográfica, que se baseia no estudo de cenários alternativos futuros e estabelece mentas específicos de desenvolvimentos, seja de crescimento econômico, equidade social e sustentabilidade ecológica, no âmbito de uma bacia hidrográfica; $2^{\circ}$ ) a tomada de decisão, através de deliberações multilaterais e descentralizadas, baseada por exemplo na participação de representante de instituições pública e privadas, usuários e comunidade, além das classes políticas e empresarias atuantes na bacia; $3^{\circ}$ ) o estabelecimento de instrumentos legais e financeiros, que são baseados no planejamento estratégico para implementação de planos e programas de investimentos(LACERDA, p.26).

A bacia hidrográfica é uma unidade regional de planejamento e gerenciamento das águas, que resulta na delimitação de Unidades de Gerenciamento de Recursos Hídricos, cujos órgãos consultivos e deliberativos de gerenciamento são denominados Comitês de Bacias Hidrográficas $(\mathrm{CBH})$, baseando-se no tripé descentralização, participação e integração, enfatizando os aspectos qualitativos e quantitativos das águas através de ações que promovam os usos múltiplos dos recursos hídricos (JACOBI, 2007).

É importante ressaltar que gerenciar uma bacia hidrográfica impõe abordar todos seus elementos (água, litologia, relevo, solo, flora, fauna, agropecuária, indústrias, urbanização, etc.) e compreendê-la como uma totalidade composta por elementos naturais e sociais, inter-relacionados e dinâmicos. Os comitês representam nessa direção uma engenharia institucional que busca garantir espaços participativos transparentes e pluralistas, na perspectiva de sustentabilidade 
e justiça social, configurada pela articulação entre complexidade administrativa e democracia (JACOBI, 2007).

Segundo Brasil (2006), para implantação da gestão descentralizada e participativa dos recursos hídricos, faz-se necessário garantir estrutura e formação para as entidades públicas encarregadas da implementação e do acompanhamento da Política de Recursos Hídricos e de seus instrumentos, sem eliminar a necessidade de fortalecimento de todas as partes do Sistema.

Assim, o processo de gestão integrada de bacias hidrográficas, por definição, deve busca metas de aproveitamento dos recursos da bacia (crescimento econômico) e de manejo com a finalidade de preservá-las, conservá-las ou protegê-las (sustentabilidade ambiental) (LACERDA, 2003).

A participação social no âmbito da política pública de gestão de recursos hídricos vem dar legitimidade e sustentabilidade às decisões, na busca de soluções harmonizadas para os problemas dos recursos hídricos, culminando na gestão de conflitos e no estabelecimento de compromissos e pactos cooperativos (BRASIL, 2006).

Deste modo, uma gestão participativa é um processo decisório aberto aos diferentes atores sociais vinculados ao uso da água, nos quais se reveem as atribuições do Estado, o papel dos usuários e o próprio uso da água (JACOBI, 2007).

Lacerda (2003), afirma ainda que a participação é uma decisão da sociedade e só ocorre efetivamente quando os grupos sociais percebem e aceitam os motivos a serem definidos, pois só assim cria-se condições para o desenvolvimento de um planejamento que atenda aos interesses e necessidade das comunidades envolvidas.

\section{Materiais e Métodos}

As atividades foram desenvolvidas de agosto/2015 a julho/2016, nas áreas de armazenamento e transposição de recursos hídricos do interior da Paraíba assistidas pelos sistemas de armazenamento e transposição do Rio São Francisco na sub-bacia do rio piranhas no município de São José de Piranhas, na Paraíba e conduzidas pela orientação da pesquisa quali-quantitativa.

Como estratégias metodológicas, foram adotados: análise de conteúdo e o estudo de caso. A análise de conteúdo é um método de tratamento e análise de informações, colhidas por meio de técnicas de coleta de dados, consubstanciadas em um documento. A técnica se aplica a análise de textos escritos ou de qualquer comunicação (oral, visual, gestual) reduzida a texto ou documento, com objetivo de compreender criticamente o sentido das comunicações, seu conteúdo manifesto ou latente, as significações explícitas ou ocultas (CHIZZOTTI, 1995, p.98).

O estudo de caso é uma estratégia metodológica na qual o pesquisador investiga um fenômeno dentro do seu contexto real, com pouco controle sobre seus eventos e manifestações. É uma estratégia sustentada por uma plataforma teórica, reúne o maior número possível de informações, em função das questões e proposições orientadoras do estudo, por meio de diferentes técnicas de levantamento de dados e evidências. Permite rastrear processos de mudança, identificando e analisando as forças históricas, pressões contextuais e a dinâmica dos grupos em uma ou mais organizações (GODOI, 2006; MARTINS, 2008).

A aproximação com a área de estudo (Vilas Produtivas Rurais) se deu numa prática interativa entre estudos teóricos e investigação no campo. Durante a pesquisa foram estudados os aspectos ecológicos e socioambientais de áreas assistidas por sistema adutor que subsidiarão ao processo de gestão participativa e desenvolvimento sustentável para a região. Neste mecanismo o saber 
acadêmico foi construído com base na experiência com a investigação científica de fenômenos regionais decorrentes da construção de adutoras em comunidades do semiárido paraibano.

Foi analisado nessa pesquisa o projeto de implementação de sistemas de armazenamento e transposição já executados e em fase de execução, através de estudos em documentos técnicos - o relatório de impacto ambiental do Projeto de Integração do Rio São Francisco com Bacias Hidrográficas do Nordeste Setentrional - RIMA e o Programa de Reassentamento das Populações - PBA08, para identificar as questões sociais e ambientais apontados no projeto. Também foram feitas visitas nas Vilas Produtivas Rurais utilizando como técnicas de apreensão de dados, observações, registros de imagens e entrevistas semiestruturadas com ênfase na repercussão socioambiental dos sistemas implantados para abastecimento hídrico em comunidades do semiárido. Entendemos que os estudos decorrentes desta pesquisa vão contribuir para gestão ambiental e participativa de recursos hídricos na perspectiva da sustentabilidade.

\section{Resultados e Discussões}

\section{Cenário Socioambiental Expresso em Documentos Oficiais e Revelado no Percurso da Implementação do Projeto - fase de construção do canal.}

No que concerne aos impactos ambientais decorrentes da implementação do Projeto de Integração do Rio São Francisco com Bacias Hidrográficas do Nordeste Setentrional foram detectados no RIMA - Relatório de impacto ambiental, 44 impactos, sendo 23 de maior relevância, dos quais 11 são relevantes como positivos e 12 relevantes como negativos. Para a avaliação desses impactos o MI contratou as empresas Ecology Brasil, Agrar Consultoria e Estudos Técnicos e JP Meio Ambiente e delimitou duas unidades de análise: a Área de Influência Indireta (AII) onde ocorrem os efeitos indiretos da integração das águas, e a Área de Influência Direta (AID), onde se dão as transformações ambientais diretas (ou primárias) decorrentes do empreendimento, no entorno imediato de onde serão construídos os canais.

No entanto, na Avaliação de Impactos Ambientais, o diagnóstico elaborado ficou a desejar, pois não enfatizou o meio antrópico, o patrimônio cultural, social e de subsistência da população cuja área será impactada. Segundo Silva (2005), os estudos não identificam e analisam suficientemente os potenciais impactos positivos e negativos do empreendimento. Dessa forma, não revelam a equação completa dos benefícios e ônus do empreendimento nos diferentes grupos sociais envolvidos.

Foram apreendidos na análise dos documentos (EIA/RIMA) os seguintes aspectos e repercussão: Aspectos socioambientais - ruptura das relações sócio comunitárias durante a fase de execução da obra; Aspectos Ecológicos - riscos em relação a introdução de espécies de peixes potencialmente daninhas ao homem nas bacias receptoras e modificação do regime fluvial das drenagens receptoras; Aspectos Econômicos - perda temporária de empregos e renda por efeito das desapropriações e introdução de tensões e riscos sociais durante a fase de implementação da obra.

Como resposta aos aspectos ecológicos os funcionários das empresas prestadoras de serviços ao canteiro de obras no município de São José de Piranhas se pronunciaram que haveria a implantação do sistema de monitoramento das vazões excedentes considerados canais naturais para açudes de maior porte como o Armando Ribeiro Gonçalves. Declararam a existência de 
um programa de Educação Ambiental previsto que evitará o surgimento de processos erosivos e degradadores que venham a comprometer o novo regime fluvial - esta medida está expressa no RIMA. Quanto à perda da vegetação nativa pelo desmatamento, embora tenham relatado a ocorrência de planos de recuperação (Plano de recuperação das áreas degradadas - PRAD), não foi perceptível durante a visita realizada no local.

Com relação aos moradores, muitos tiveram que se deslocar de suas casas para a realização das obras. O governo fez uma proposta para as famílias ficarem reassentadas em outro local e esse processo ainda continua até as obras serem concluídas e com essas desapropriações muitos dos moradores ficaram desempregados em uma porcentagem de mais de $51 \%$, porém $50 \%$ das obras realizadas foram mão-de-obra local, o que significa que boa parte da população teve seu trabalho garantido.

A preocupação evidenciada é na forma como as famílias iriam ser reassentadas e como o gerenciamento da área irá ocorrer. São questões que não estão claras nos documentos, setor ou gestor hora atuante no canteiro de obras estudado.

Configura-se, portanto, a execução de um projeto de grande porte, com repercussões diversas na vida da população e no ambiente semiárido cujos efeitos estão a depender da forma a ser gerenciada a partir das obras de engenharia. O desafio é perceptível e programas de intervenção na área tecnológica, educativa e econômica devem constituir o processo de instalação funcional do empreendimento.

Problemas como desapropriação de terras e remoção da população; alterações das comunidades biológicas terrestres e aquáticas; perdas de hábitats da fauna da região pelo desmatamento, desconfiguração do cenário vegetal do bioma Caatinga constituem os impactos negativos cujas medidas mitigadoras precisam ser efetivadas na totalidade, como projetos em execução. Configurase um cenário desafiador aos gestores e à comunidade que alimentam a expectativas de alcançarem um desenvolvimento sustentável para a região a partir de tal empreendimento.

\section{Fases de Reassentamentos de Famílias Beneficiadas pela Transposição do Rio São Francisco - Vilas Produtivas Rurais (VPR), PB.}

O estudo revelou que foram propostas quatro opções de reassentamento que consistem, nas modalidades: reassentamento em áreas remanescentes (transferência voluntária das famílias proprietárias de terras para áreas não afetadas da propriedade 'remanescentes'); auto reassentamento famílias residentes na área a ser desapropriada, cujo valor da indenização de terras e/ou benfeitoras for superior a $\mathrm{R} \$ 30.000,00$ (trinta mil reais); reassentamento coletivo rural (visa possibilitar a reprodução das relações sociais nos novos locais de moradia e produção, mantendo os vínculos de parentesco e de vizinhança existentes na área, para isso foram selecionadas preliminarmente, a partir do zoneamento da área de 2,5km em cada uma das margens dos canais, elaborado no Projeto Básico Ambiental - PBA, áreas com potencial para agricultura com base no potencial para irrigação do solo) e reassentamento em áreas urbanas (famílias em situação de risco social poderão ser identificadas alternativas individuais de relocação urbana em centros vizinhos). 
Nesta perspectiva, o PBA-08 entende ser necessário promover o reassentamento, conforme as premissas expostas no programa de reassentamento, considerando a participação das comunidades afetadas no processo de detalhamento, implantação e monitoramento do Programa.

\section{Aspectos Gerais das Vilas Produtivas Rurais}

De acordo com a definição encontrada no Programa de Reassentamento de Populações, uma Vila Produtiva Rural pode ser entendida como: "as áreas rurais adquiridas pela União dotadas de infraestrutura comunitária e de produção, destinadas ao reassentamento das famílias residentes na faixa de obra que atendam aos critérios de elegibilidade estabelecidos pelo empreendedor".

Existem quatro Vilas Produtivas Rurais - VPRs no município de São José de Piranhas, e são elas: Irapuá I, Irapuá II, Cacaré e Quixeramobim.

As vilas produtivas rurais foram escolhidas como modelo para instalação da modalidade de reassentamento coletivo rural, e para sua construção selecionou-se dezoito áreas ao longo da faixa de 2,5 $\mathrm{km}$ a partir de cada uma das margens do canal, elas se caracterizaram pela presença de um lote urbano onde serão construídas as casas para as famílias, também escola, posto de saúde, área de lazer, etc., como foi possível constatar com as visitas e registros de imagens nas Vilas Produtivas de são José de Piranhas e também um lote de produção irrigado externamente que ainda não haviam sido entregues as famílias na época.

Encontra-se nos registros do Programa de Indenização e Reassentamento a quantidade de 296 imóveis afetados pelo projeto no município de São José de Piranhas - PB, consistindo na maior área afetada se comparada aos outros municípios totalizando 5.172,584ha. Este é também o município com maior contingente de famílias a serem relocadas pelo empreendimento, são 260 famílias no total, sendo 84 proprietários e 176 não proprietários.

Comparando esses dados encontrados no programa de reassentamento das populações, com informações adquiridas ao visitar o canteiro de obras, observam-se algumas diferenças como, por exemplo, o número de casas construídas nas quatro agrovilas somam 217 ao todo, e são distribuídas da seguinte forma em cada VPR: 30 casas na Vila Irapuá I, 20 casas na Vila Irapuá II, 120 casas na Vila Jurema e 47 casas na Vila Quixeramobim, isso de certa forma difere do que consta no PBA-08 cujo o número total é de 260 famílias desapropriadas no município, o que é explicado pelo o fato de algumas famílias não se enquadrarem na modalidade de reassentamento e também optaram por receber indenização em dinheiro, abrindo mão da casa na Vila.

\section{A Seleção de Reassentamento das Famílias para as Vilas Produtivas Rurais}

No programa de reassentamento de populações é previsto a preservação dos laços de parentesco e de vizinhança nos locais de reassentamento rural coletivo, porém essa é uma realidade não observada se analisarmos os critérios de seleção utilizados para transferência das famílias em cada Vila e também para as casas. Isso pode ser constatado na fala de moradores entrevistados que explicam como ocorreu essa transferência.

Desde o início eu escolhi essa vila, depois como não dava pra vir todo mundo pra cá, eles colocaram aqui o pessoal que já tinha sua casa própria e nas outras agrovilas quem era morador (Entrevistado Irapuá I, 2016). 
A gente escolheu vir pra essa porque é mais próxima à cidade é bem melhor pra trabalhar, eu tenho dois filhos que eram pra esta aqui à primeira vez que a gente fez os cadastros foi dado o nome pra cá, mais como teve um problemazinho que queria vir todo mundo, ai eles selecionaram os que eram donos de sua casa e terra pra permitir vir pra cá e os que eram morador como já era diferente né eles tiraram, esse ai do lado é filho meu mais ele tinha a casa dele o outro não tinha casa própria e foi para o Cacaré (Entrevistado Irapuá I, 2016).

A minha esposa tinha direto de puxar até cinco pessoas, a gente puxou a irmã dela e outro vizinho ali. É o seguinte uma suposição pra você entender, a nossa foi a casa 8 ela falou você gostaria de botar alguém do seu lado, ai na 9 ficou eu na 10 ficou outro e na 11 ficou o outro entendeu, só algumas pessoas são sorteadas e puxa o resto. Ali na rua de cima tem um pai e o resto e tudo filho (Entrevistado Cacaré, 2016).

Como é possível de ser entendido a partir dessas falas o principal critério não foi o parentesco e nem a vizinhança do local onde moravam anteriormente, mas o fato da família ser ou não proprietária da terra onde se encontrava. Isso não contribui para que o processo seja adequado às suas características socioeconômicas e culturais e dificulta a garantia de condições e perspectivas melhores do que as que têm atualmente.

\section{Monitoramento, Organização Social e Assistência ás Vilas Produtivas Rurais}

São muitos os órgãos envolvidos no programa, especialmente nas etapas de implantação dos reassentamentos e de reinserção socioeconômica dos reassentados nos novos locais de moradia, mas as famílias não possuem o conhecimento sobre quais estão atuando ou qual função deveriam exercer nas Agrovilas. É percebido uma enorme falta de informação por parte delas, que é esboçado por suas respostas generalizadas de que o Ministério da Integração é a única instituição atuante.

O processo de monitoramento e avaliação, de acordo com os moradores, é feito pelo Ministério da Integração e pela associação dos morados de São José de Piranhas e mostrouse eficiente atendendo o previsto, que seria desenvolvido durante o transcorrer do Programa de Reassentamento. Isso é importante, pois, transmite segurança às famílias que estão sendo acompanhadas.

Existe uma associação dos trabalhadores em processo de organização para decidir os representantes em cada vila, segundo os entrevistados e, através da associação eles podem exigir seus direitos aos representantes legais do programa, reclamar de possíveis insatisfações e sugerir melhorias nas Vilas.

De acordo com o programa, os serviços de assistência técnica a serem prestados buscam uma conscientização dos produtores para o uso racional e eficiente da água e do solo, de modo a assegurar a produtividade sem comprometer as condições ambientais. Isso está sendo trabalhado continuamente nas várias reuniões com as famílias, em oficinas e cursos preparatórios, visando à boa convivência e à educação ambiental, porém praticas como o desmatamento ainda são bastante visíveis. Percebe-se também falta de incentivo para mudar a postura ambiental dos moradores.

Algo também a se destacar é a falta de lixeiras nas ruas em todas as agrovilas e a preocupação dos moradores em não desmatar as árvores marcadas e as áreas delimitadas pelo IBAMA dentro 
das agrovilas, mas não pela consciência da boa pratica ambiental trabalhada nos cursos, e sim pelo medo da punição e indenização imposta a quem descumprir essas exigências.

A assistência produtiva de como lidar com a terra era inexistente, isso se explica segundo os produtores entrevistados, porque esses cursos só ocorreriam quando eles estivessem em posso das terras para começar trabalhar.

\section{Grau de Satisfação e Expectativa das Famílias Reassentadas}

De modo geral, as famílias entrevistadas se mostram bem satisfeitas com o sistema de vilas produtivas, pois as condições de vida melhoraram para muitas que não possuíam casa própria e moravam em condições precárias no local onde viviam anteriormente. Por outro lado, mesmo diante de uma boa aceitação dessa nova realidade existe a saudade do lugar onde nasceram e se criaram.

Em relação às reclamações as casas das Vilas de acordo com os reassentados foram projetadas apenas para a seca, sem levar em consideração a época de chuvas de verão na região e isso causou alguns problemas com vazamentos, as fossas sépticas também são bastante criticadas por terem sido feitas muito próxima à cozinha das casas causando mau cheiro.

Fazendo um balanço de todos os prós e contras e como a qualidade de vida das famílias mudou em relação as suas antigas moradias, todos apresentam grande expectativa de melhorias e aguardam a agua da transposição ansiosos para voltar a trabalhar a terra.

\section{Conclusão}

A inserção geográfica predominante do território paraibano no semiárido nordestino sempre representou, desde os primórdios da colonização, um grande obstáculo para o estabelecimento de um perfil socioeconômico produtivo (PARAÍBA, 2002).

O projeto de transposição do Rio São Francisco vislumbra-se como a solução mais eficiente e estruturante para aumentar a oferta de água com garantia para uma população e toda uma região que sofrem com a seca. No entanto, essa solução não é isolada, ela vem somar e dar maior estrutura aos compromissos e ações já existentes na região de combate à seca e a da má distribuição de água. Vem garantir água para uma estrutura de retenção e rede de distribuição já existente na região formado por rios, açudes e adutoras.

Para que os objetivos da Transposição do Rio São Francisco sejam alcançados ele deve ser implantado de forma adequada e consciente, alicerçado em uma Gestão eficiente constituída por uma Política, que estabelece as diretrizes gerais, um Modelo de Gerenciamento, que estabelece a organização legal e institucional e um Sistema de Gerenciamento, que reúne os instrumentos para o preparo e execução do Planejamento do Uso, Controle e Proteção das Águas. E, principalmente, que seja implantada com a participação da população beneficiada.

Esses desafios são lançados aos gestores, que devem trazer a tona não só os aspectos ambientais, mas os aspectos em evidência com os moradores, para que eles possam também participar das decisões, intervindo como agentes de interesse mútuos, numa categoria de gestão participativa. $\mathrm{O}$ projeto surge como uma solução para fornecer água à população de uma região vulnerável a seca e sofre com a escassez, contribuindo para o desenvolvimento socioeconômico do semiárido nordestino, assim como, para gerar impactos socioambientais nas áreas assistidas pelo projeto. 
Como estratégia para reduzir esses impactos, criou-se um conjunto de programas ambientais, como o programa de reassentamento das populações, que tem por objetivo propiciar as famílias afetadas pela transposição condições adequadas para o reassentamento em Vilas Produtivas Rurais.

São quatro dessas vilas no município de São Jose de Piranhas no interior da Paraíba Irapuá I, Irapuá II, Cacaré e Quexeramobim, cujas famílias reassentadas entrevistadas apresentam alguns laços de parentesco e de vizinhança rompidos, pouca informação, algumas insatisfações e expectativas sobre o programa.

Todas essas questões proporcionam entendimento dos desafios para a implementação desse projeto e as demandas dessas populações, que possibilidades um processo de gestão participativa na área na perspectiva de um desenvolvimento sustentável.

\section{Agradecimentos}

Ao Centro de Formação de Professores da Universidade Federal de Campina Grande, pela viabilidade concedida; ao $\mathrm{CNPq}$, pela manutenção das bolsas PIBIC e produtividade em pesquisa, e aos colegas do Grupo de Pesquisas Ambientais para o Desenvolvimento Sustentável do Semiárido GPA/CFP/UFCG, pelo conhecimento compartilhado.

\section{Submissão ao Comitê de Ética}

A pesquisa foi aprovada pelo Comitê de Ética em Pesquisa do Centro de Formação de Professores da UFCG, em 17 de abril de 2015, com registro CAAE 43023315.2.0000.5575.

\section{Referências}

ALVES-MAZZOTTI, Alda Judith; GEWANDSZJDER, Fernando. O Método nas Ciências Naturais e Sociais: pesquisa quantitativa e qualitativa. 2. ed. São Paulo: Pioneira, 1998.

BRASIL. Ministério do Meio Ambiente. Agenda 21. Capítulo 18. Proteção da Qualidade e do Abastecimento dos Recursos Hídricos: Aplicação de Critérios Integrados no Desenvolvimento, Manejo e Uso de Recursos Hídricos. Disponível em: < http: // www. mma.gov.br/por/SE/ agen21/cap18.html > Acesso em: 26 de agosto de 2002.

BRASIL. Lei n ${ }^{\circ} 9.433$ / 97. O Conselho Nacional de Recursos Hídricos - Órgão do sistema nacional de gerenciamento de recursos hídricos., Brasília, DF, novembro de 1998. Disponível em: <http: // www.cnrh-snh.gov.br > Acesso em: 23 de agosto de 2003.

BRASIL. Lei n ${ }^{\circ} 9.433$ / 97. Política Nacional de Recursos Hídricos. Plano Nacional de Recursos Hídricos, Planos de Recursos, Enquadramento dos Corpos d'Água, Outorga, Sistema de Informações, Brasília, DF, 1997. Disponível em: <http: // www.pnrh.cjb.net/ > Acesso em: 23 de agosto de 2003. 
BRASIL./ Ministério do Meio Ambiente. Projeto de Integração do Rio São Francisco com Bacias Hidrográficas Setentrional. Relatório de Impacto Ambiental. Ecology Brasil, 2004.

BRASIL. / Ministério do Meio Ambiente. Plano Nacional de Recursos Hídricos: Panorama e estado dos recursos hídricos do Brasil. Volume 1- Brasília: MMA, 2006.

BRASIL. Lei n ${ }^{\circ} 9.433$ / 97. Política Nacional de Recursos Hídricos. Legislação, Brasília, DF, 2001. Código de Águas. Disponível em: <http://www.planalto.gov.br/ccivil_03/ decreto/d24643.htm>. Acesso em 13 Dez. 2012

CHIZZOTTI, Antonio. Pesquisa em ciências humanas e sociais - 2. Ed. - São Paulo: Cortez, 1995.

Comissão Mundial Sobre o Meio Ambiente e Desenvolvimento. Nosso Futuro Comum. - ed.- Rio de janeiro: Editora da fundação Getulio Vagas, 1991.

FEITOSA Antônia Arisdélia Fonseca Matias Aguiar. Estudos Ecológicos e Socioambientais em Áreas Assistidas por Sistemas de Armazenamento e de Transposição de Águas na Região Semiárida. Projeto de Pesquisa PIVIC/UFCG/CFP (2012-2013), Cajazeiras - PB. 14 p.

LACERDA, A. V. A Semi-Aridez e a Gestão em Bacias Hidrográficas: visões e trilhas de um divisor de ideias. João Pessoa, PB: Universitária UFPB, 2003. 164 p.

GODOI, Christiane Kleinübing; BANDEIRA-DE-MELO, Rodrigo; SILVA, Anielson Barbosa da. (Orgs.). Pesquisa Qualitativa em Estudos Organizacionais: paradigmas, estratégias e métodos. São Paulo: Saraiva, 2006.

JACOBI, Pedro Roberto. BARBI, Fabiana. Democracia e participação na gestão dos recursos hídricos no Brasil. Florianópolis: Rev. Katál, v. 10 n. 2, p. 237-244, 2007. Disponível em: http://www.scielo.br/pdf/rk/v10n2/a12v10n2.pdf. Acesso em: 22 de mai 2013.

KUMMER, L. Metodologia participativa no meio rural: uma visão interdisciplinar. Conceitos, ferramentas e vivências. - Salvador: GTZ, 2007.155p.

LACERDA, A.V. A Semi-Aridez e a Gestão em Bacias Hidrográficas: visões e trilhas de um divisor de idéias. João Pessoa, PB: Universitária. UFPB, 2003.164 p.

MAIA MELO ENGENHARIA Ltda. Elaboração de estudos técnicos preliminares de viabilidade e do projeto básico do Sistema Adutor Capivara - Relatório Final de Viabilidade- RFV.2006. Disponível em: < http://www.aesa.pb.gov.br/proagua/ > Acesso em: 10 de Dezembro de 2012. 
MACEDO, Roberto Sidnei. A Etnopesquisa Crítica e Multirreferencial nas Ciências Humanas e na Educação. Salvador: EDUFBA, 2000.

MARTINS, Gilberto de Andrade. Estudo de Caso: uma estratégia de pesquisa. 2. ed. São Paulo: Atlas, 2008.

MARTINS, Joel; DICHTCHEKENIAN, Maria Fernanda S. Farinha Beirão. (Orgs.) Temas Fundamentais de Fenomenologia. São Paulo: Centro de Estudos Fenomenológicos de São Paulo, 1984.

MAY,Tim. Pesquisa Social: questões, métodos e processos. 3. ed. Porto Alegre: Artmed, 2004.

MINAYO, Maria Cecília de Souza. O Desafio do Conhecimento: pesquisa qualitativa em saúde. 5.ed. São Paulo-Rio de Janeiro: HUCITEC-ABRASCO, 1998.

Ministério da Integração Nacional. Projeto de Integração do Rio São Francisco com Bacias Hidrográficas do Nordeste Setentrional. Relatório de Impacto Ambiental (RIMA). Brasília, 2004. Disponível em: <http://www.integracao.gov.br/relatorio-de-impactoambiental-rima $>$ Acesso em 24 de Outubro de 2012.

Ministério da Integração Nacional. Projeto de Integração do Rio São Francisco com Bacias Hidrográficas do Nordeste Setentrional. Programa de Reassentamento das Populações. Brasília, 2005. Disponível em: < http://www.mi.gov.br/web/projeto-sao-francisco/38programas-ambientais/programa-de-reassentamento-de-populacoes $>$ Acesso em 01 de Setembro de 2015.

SILVESTRE, Maria Elisabeth Duarte. Código de 1934: água para o brasil industrial. Revista geo-paisagem (on line). Ano 7, no 13, 2008. Disponível em: < http://www.feth. ggf.br/\%C3\%81gua.htm > . Acesso em: 17 de Dezembro de 2012.

LACERDA, A. V.A Semi-Aridez e a Gestão em Bacias Hidrográficas: visões e trilhas de um divisor de ideias. João Pessoa, PB: Universitária. UFPB, 2003. 164 p.

Ministério da Integração Nacional. Projeto de Integração do Rio São Francisco com Bacias Hidrográficas do Nordeste Setentrional. Relatório de Impacto Ambiental (RIMA). Brasília, 2004. Disponível em: <http://www.integracao.gov.br/relatorio-de-impactoambiental-rima > Acesso em 24 de Outubro de 2012. 